\title{
Ovarian Metastasis of a Lymphoma
}

\author{
Viroj Wiwanitkit \\ Wiwanitkit House, Bangkok, Thailand
}

Key Words
Lymphoma · Ovary · CA125

Dear Editor,

I read with great interest the recent report on ovarian metastasis of a lymphoma by De Gregorio et al. [1]. The authors concluded that 'Literature research shows that elevated CA125 levels are often found in lymphomas [1].' Indeed, lymphoma is an important differential diagnosis for pelvic masses with elevated CA125 levels [2]. In laboratory medicine,

CA125 is not an ideal cancer biomarker. Increased levels of CA125 can also be detected in ovarian non-malignant tumors as well as other cancers not located in the pelvic area [3]. In the latter, the cancers might coexist with the pelvic mass. These conditions have to be kept in mind by the practitioner faced with a case of pelvic mass with increased CA125 levels.

\section{References}

1 De Gregorio N, Schmitt W, Kreienberg R, Wulff C: Ovarian metastasis of a lymphoma presenting as primary ovarian cancer. Onkologie 2009;32:752-3.
2 Perlman S, Ben-Arie A, Feldberg E, Hagay Z: Non-Hodgkin's lymphoma presenting as advanced ovarian cancer - a case report and review of literature. Int J Gynecol Cancer 2005;15:554-7.
3 Moss EL, Hollingworth J, Reynolds TM: The role of CA125 in clinical practice. J Clin Pathol 2005;58:308-12.

\section{KARGER}

(c) 2010 S. Karger GmbH, Freiburg

Fax +497614520714 